University of Nebraska - Lincoln

DigitalCommons@University of Nebraska - Lincoln

Faculty Publications, UNL Libraries

Libraries at University of Nebraska-Lincoln

June 1994

Recognizing and Managing Multiple Organizational Approaches

Joan Giesecke

Universityof Nebraska-Lincoln, jgiesecke1@unl.edu

Follow this and additional works at: https://digitalcommons.unl.edu/libraryscience

Part of the Library and Information Science Commons

Giesecke, Joan, "Recognizing and Managing Multiple Organizational Approaches" (1994). Faculty Publications, UNL Libraries. 86.

https://digitalcommons.unl.edu/libraryscience/86

This Article is brought to you for free and open access by the Libraries at University of Nebraska-Lincoln at DigitalCommons@University of Nebraska - Lincoln. It has been accepted for inclusion in Faculty Publications, UNL Libraries by an authorized administrator of DigitalCommons@University of Nebraska - Lincoln. 


\title{
Recognizing and Managing Multiple Organizational Approaches
}

\author{
Joan Giesecke
}

Organizational theory today includes a number of analytical models which provide descriptions of how organizations function as well as prescriptions as to how organizations should function. Five organizational models seem particularly appropriate to academic libraries. The rational model describes organizations as value-maximizing units which are task oriented. The political bargaining model views organizations as arenas for conflict and bargaining where participants form coalitions and interest groups to achieve their own ends. The garbage can model views the organization as a chaotic mess where independent actors pursue individual, yet changing goals and decisions are mostly a function of timing. The bureaucratic model emphasizes roles, rules, and routines as the keys to organizational actions. Finally, the participatory or teamwork model, which has become a major focus in today's environment, assumes organizational goals are truly shared and that organizations can meet both individual and organizational needs.

The astute manager faces the challenge of recognizing when there are diverse approaches present in the organization and then must devise strategies for working with a mixture of cultures in order to achieve organizational goals. To help managers untangle

Joan Giesecke is Associate Dean for Collections and Services, University of Nebraska-Lincoln, Lincoln, NE.

[Haworth co-indexing entry note]: "Recognizing and Managing Multiple Organizational Approaches." Giesecke, Joan. Co-published simultaneously in Journal of Library Administration (The Haworth Press, Inc.) Vol. 20, No. 2, 1994, pp. 29-46; and: The Dynamic Library Organizations in a Changing Environment (ed: Joan Giesecke) The Haworth Press, Inc., 1994, pp. 29-46. Multiple copies of this article/chapter may be purchased from The Haworth Document Delivery Center [1-800-3-HAWORTH; 9:00 a.m. - 5:00 p.m. (EST)].

(C) 1994 by The Haworth Press, Inc. All rights reserved. 
the web that is organizational processes, this article will describe a framework for identifying organizational processes or models, describe and clarify the participatory model as it is being used today, and provide managers with some advice on developing strategies for working within today's complex organizations. Because decision making is one of the primary activities in an organization, the framework for analysis is built around the decision-making processes within the organization or unit. ${ }^{1}$

\section{FRAMEWORK FOR ANALYSIS}

The idea of examining organizational processes by comparing competing organizational models is well established. ${ }^{2}$ The process allows us to identify organizational assumptions and assess the impact on our conclusions. Because decision making is a fundamental aspect of a manager's job, and the processes used to make decisions impact how organizational objectives are attained, decisionmaking processes will be the focus used in analyzing different organizational models that are descriptive of today's academic libraries.

Classic models of decision making view the process as a series of steps or stages that are followed. Problems are identified, alternatives are generated and ranked, and the choice is made that will maximize benefits or yield the highest expected return. The process is orderly and efficient.

In spite of this prescriptive model studies of how organizations actually function showed that the process is messy, disorderly, and difficult to analyze. ${ }^{3}$ Understanding organizational context is as important as understanding the process in trying to describe organizational decision making. Criticism of the rational model led to a variety of models that explain aspects of the organization that are not well covered in the classical model.

The framework for this study begins with concepts within the models rather than with the steps in the decision-making process. This was done to capture the context within which decisions are made as well as to analyze the process of decision making. The framework includes three categories of variables that can be used to help distinguish among the different models. These variables are characteristics of the organization, characteristics of the decision- making process and the method by which decisions are made. The characteristics of the organization are divided into four categories: the degree of goal ambiguity, degree of certainty about organizational processes, degree of structure in the organization, and adequacy of organizational resources.

Goal ambiguity is described as a continuum from well-defined to ill-defined goals for the organization or for participants. Organizational processes, or understanding how the organization achieves its objectives, is examined on a continuum from certain to uncertain. Organizational structure is viewed from structured to unstructured, and adequacy of resources is described on a continuum from excess to scarce.

The characteristics of the decision-making process are also divided into four variables: interdependence of participants, diffusion of power, use of information, and participants' perception of the issue. The degree of interdependency of participants is measured from independent to interdependent. The diffusion of power in the organization will be examined on a continuum from centralized to dispersed. The use of information by participants is examined on a continuum from gathered and used to not used, while the participants' perception of the issue will be examined on a continuum from important to unimportant.

The method by which the process solves problems is examined to determine what the model predicts about the outcome of the decision-making process and about how participants make choices. Does the model account for the results of decision-making processes?

In the next section this framework will be used to describe five major organizational models and will outline how managers can identify these processes and distinguish among the different approaches. Table 1 summarizes the key concepts of each model.

\section{MODELS}

\section{Rational Model}

The rational model assumes that organizational goals are clear and that all participants share the same goals. ${ }^{4}$ It assumes that participants understand the linkages between action and outcomes 


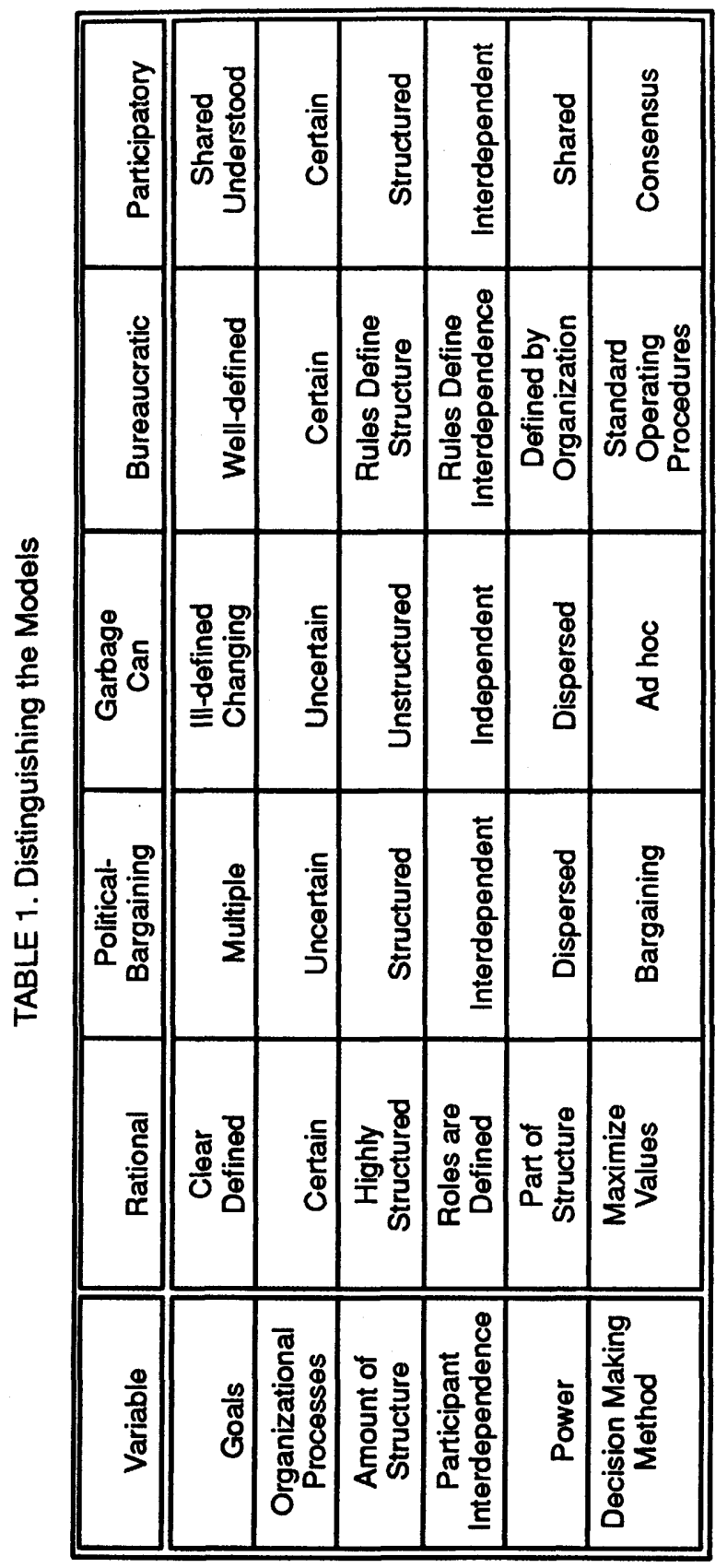

and that the organizational processes are clear. The organization is seen as structured where the structure defines participants' roles and the rules explain organizational processes. Organizational resources are assumed to be in balance. That is, in the long run, demand for resources will match the supply of resources. In viewing the decision-making process, the rational model assumes participants' roles are clear, and does not address the issue of interaction among participants. The issue of power is not addressed since the structure of the organization defines participants' relationships. With this model information is a key element in decision making with information being gathered and used in the process. Information is assumed to be a free good, widely available and shared. The model does not address the issue of the content of the decision. Issues may be important or unimportant to participants. In the rational model the outcomes of the decision-making process are chosen on the basis of value maximization. Participants choose the alternatives with the highest rate of return. Although the rational model has been presented as a prescriptive view of the organization, it does not explain how complex organizations actually make decisions in today's changing environment. Critics of the rational model have developed approaches to describing organizational process that may more closely match the reality of today's organizations. These include the political bargaining model, the bureaucratic model and the garbage can model.

\section{Political Bargaining Model}

The political bargaining model grew out of dissatisfaction with the rational model, specifically the inability of the rational model to explain decision making in public organizations and the inadequacy of the rational model to account for the impact of power differences within the organization. ${ }^{5}$ In the political bargaining model the organization is described as a coalition of diverse interests. Organizations have multiple goals while participants are seen as having consistent, yet different goals. Behavior is purposeful and individuals act to achieve their own objectives. However, because the decision-making process involves multiple participants with conflicting objectives, decision makers may be uncertain as to how any given action will impact the process.

Nonetheless the process is structured in that organizational rules 
determine who can participate in the process and how the process will unfold. Participants' positions within the hierarchy, deadlines, and rules structure the process. Resources are assumed to be scarce so that participants come into conflict as they seek to meet their own needs.

Throughout the process, participants are interdependent. Individual actions are taken in response to actions by other players. Power is a key element in the process. Managers must assess how power is distributed throughout the organization to be able to successfully plan their strategies.

Information also becomes a key element in the process. Information is a resource to be hoarded and used as part of the negotiation process.

Finally, if the issue is seen as important by the participants, participants will enter into bargaining and negotiating activities, coalition building efforts or advocate incremental strategies to gain their own objectives. The negotiating game will continue as long as participants want to bargain and be a part of the process. Resolution comes when players reach a point of compromise and agreement. This will not necessarily resolve the problem at hand because participants are free to reopen the issue and reenter negotiations if they feel they can achieve a better end.

In summary, the political bargaining model assumes participants will bargain and negotiate within the organization setting to achieve their own self-interest. Behavior is purposeful although the organization may not appear as such as participants pursue conflicting strategies. The model explains the decision-making process when power is dispersed, participants are interdependent and care about the issues at hand, and are willing to engage in bargaining strategies to achieve their goals.

\section{Garbage Can Model}

The garbage can model of decision making presents a very different view of the organization and of participants' behavior. ${ }^{6}$ Here organizations are described as organized anarchies where organizational goals are ambiguous, participants are unable to predict how actions impact outcomes, and where participants' interest in a given issue is fluid and changing. Within this context, organizational and individual goals are ambiguous and can change within a decisionmaking process. Organizational structure has minimal impact on how the organization functions. Resources are defined as the number of decision-making opportunities (or meetings) available to participants. Resources can range from excessive, where everyone who wants to participate in a decision-making process may do so, to scarce where individuals will negotiate and bargain to be able to participate in the process.

Participants in the process are independent of each other, engaging in decision-making opportunities only as long as the issue holds their interest. Power is dispersed and the distribution of power may change within the process. Information is gathered and may be used or abandoned as the process continues. The issue is important to participants at that moment in time, but their interest may shift and the issue may just as easily be abandoned. Participants are easily distracted and drop out of decision-making processes when more interesting activities come along.

Within this fluid structure, problems, solutions, and participants are seen as independent streams that may come together in a decision-making opportunity. If the timing is right, a decision will be made and a problem resolved. If not, the issue may move to another decision-making opportunity, may be resolved elsewhere in the organization, or may be abandoned only to surface at a later date. The garbage can model description of the decision-making process seems almost pathological when compared to the classical models of decision making. Nonetheless the process is familiar sounding to managers and helps describe decision-making processes in complex organizations with ambiguous goals.

\section{Bureaucratic Model}

In the bureaucratic model goals are defined by the organization and are translated into rules and routines. ${ }^{7}$ The rules defining behavior and actions can be explained by looking to the standard operating procedures for the organization. Certainty abounds as participants understand how they fit within the organization and how much discretion they have in making decisions. The hierarchy is well established and defines participants' roles within the organization. Budget cycles, reporting requirements, and evaluation systems 
are used by upper-level management to structure individual behaviors. Although the model does not specifically address the issue of resources, resources are likely to be seen as adequate in that the rules of the organization will determine how resources are allocated and how demands will be met.

The rules of the organization define the relationships between participants in the organization. Participants are bound together by the rule structure and so may be seen as interdependent, depending on where they fit within the structure. Power is dispersed, but is defined by the hierarchy. In decision-making processes information will be gathered and used as defined by the routines of the organization. Issues may or may not be important to participants but will fit into the structure of the organization. Decisions are often made incrementally as there is limited flexibility within the structure. The structure allows for the coordination of actions among large groups of people within a complex organization, but it does not necessarily encourage major changes in direction.

\section{Participatory Model}

Although much has been written about the use of teams in libraries, the assumption that teams and participatory processes are inherently useful has not been well explored. ${ }^{8}$ In order to successfully employ teams in an organization, the manager needs to be sure that the organizational context supports teamwork or participatory processes. What, then, are the characteristics of the organization and of the decision-making process that are keys to participatory decision making?

Participatory decision-making process begins with the assumption that team members have shared goals. The goals become shared when individual needs and organizational goals are matched. That is, participants' needs and organizational needs intersect in a way that allows all parties in the decision-making process to accept the organizational vision and still meet individual needs. The model assumes that participants understand how their actions affect the decision-making process. There is some degree of certainty among participants about how the organization functions and how decisions are made and implemented. The organizational structure defines roles and helps determine who participates in decision-mak- ing processes, how problems are brought to the agenda and how solutions will be reached. The model also assumes that resources are not extremely scarce so that participants can achieve their goals as the organization achieves overall goals and objectives.

In examining the decision-making process, the participatory process assumes that participants are interdependent and have a strong incentive to work together. This can occur because of the task of the group, because of the placement of the team within the organization, or because participants want to work together to maintain the social structure of the team.

Power is not well-defined in this model, and in fact, is generally absent from discussions of the team process. Nonetheless, for the process to be successful, power must be shared. If participants are perceived to have significantly different amounts of power, the process is likely to break down. For example, when power is dispersed unequally, participants may move to negotiating and bargaining rather than developing a participatory process.

Information is a key element in the model as well. Information is gathered as part of the decision-making process, is shared openly among participants and is used in coming to a decision. Communication among team members is essential if team members are to work together effectively.

The issues under discussion need to be important to the participants in order to capture limited time and energy of the team. The issue itself may be important or it may be important to participants to engage in teamwork in order to maintain the social structure of the team. In other words, some members of the group may participate, not because of the issue at hand, but to maintain the team structure.

According to Bolman and Deal, in addition to looking at structure, shared goals, power, and interdependence, one other element is needed to make teams successful. ${ }^{9}$ That element is attention to the symbolic elements in the workplace. The symbolic framework examines the myths, rituals, ceremonies and stories that are an important part of the life of the organization. For teams, how members become a part of the team is important. The ritual of signing up to be a member helps the individual feel that the team is important. Diversity among team members is needed to bring in fresh perspec- 
tives and to help members feel that their contributions are unique to the group. A special language can bring a team together and foster cohesion. Stories, humor, ritual and play all help solidify the group, giving them an identity that helps frame their work together. By nurturing the symbolic aspects of the process, as well as the more common elements of structure, authority, responsibility, and power, the organization can create a context that promotes team success.

The primary method of decision making in this model is consensus. Here consensus refers to team members being willing to commit to the group decision, whether or not the minority agree with the results.

In summary, then, participatory decision making or teamwork is a process whereby interdependent team members with shared goals, shared power, and equal access to information come together to meet a goal. For important issues, the method of decision making will be consensus. For participatory processes to be successful, the organization must support and reward shared goals and teamwork.

\section{DISTINGUISHING BETWEEN DECISION-MAKING MODELS}

The organizational context becomes crucial in distinguishing between organizational models within complex organizations. More than one process may be present within the organization. Trying to merge those differences becomes a key challenge for today's manager. Trying to change the organization to make one process dominant within the organization requires a clear understanding of the key differences between the models.

Distinguishing rational, political-bargaining, garbage can, bureaucratic, and participatory models is possible by examining the goal structure of the organization and of the participants, determining the amount of interdependency among organizational members, and recognizing how power is distributed throughout the organization. When goals are ambiguous for the organization but consistent for individuals, power is dispersed, and participants are interdependent, political bargaining behavior is likely to occur. When organizational goals are ambiguous, and individuals are inconsistent in their own preferences, when members are independent, then garbage can pro- cesses may emerge. When goals are defined by the organization, routines and standard operating procedures define the structure and define participants' roles within that structure, authority is part of the routines, the need for information is reduced by the use of rules, and decisions follow from the programs and routines, then the bureaucratic model describes organizational processes. When organizational and individual goals match and are shared among all participants, power is shared and members are interdependent, then participatory processes can succeed.

\section{STRATEGIES TO USE IN EACH ENVIRONMENT}

Managers encounter problems when they try to use strategies appropriate to one context to solve problems in another context. For example, using coalition building techniques in a garbage can environment where individuals have inconsistent objectives will not be successful as individuals will move in and out of various groups without necessarily staying long enough to resolve the issues at hand. Once managers identify different models present within their organizations, they can choose appropriate strategies to use in working with the different groups within the organization.

In a political bargaining environment managers can use a variety of bargaining and game theory techniques to influence outcomes. ${ }^{10}$ Coalition building strategies, compromise proposals or choosing proposals that are "good enough" to satisfy most participants, or bargaining processes can all be effective in managing the process. Incremental solutions can also be effective in addressing pluralistic interests in complex organizations.

If garbage can processes are present, the manager faces a more difficult situation as decision making and other organizational processes are difficult to predict. ${ }^{11}$ Here, managers have three basic approaches they can use to influence organizational processes. They can add controls to try to limit the fluidness of the organization and to limit the independence of participants. They can adapt to the process by changing their style to meet the organizational approaches. This can involve setting deadlines to structure a process, spending a lot of time on a problem thereby outlasting participants who will move on to other activities, and overloading the 
system so that participants are distracted by other problems, leaving the manager to resolve the important issue at hand. Finally, in a very different approach managers can embrace the flexibility of the garbage can process and let participants act first, bringing creativity to the process while not worrying about the outcome. This type of adaptation brings chaos to the system but can promote creativity and novel solutions to organizational problems.

In a bureaucratic environment managers need to be aware of the standard operating procedures and rules of the system. Knowing how to use the organizational rules effectively is crucial for managers. Change comes by changing routines and rules. Imposing change without considering the impact on established rules will not be effective. Working with participants to analyze and change the rules and routines and adopt new standard operating procedures can be time consuming but may be more effective in the long run than imposing changes on an unwilling audience.

In participatory environments, managers are not limited to consensus building as their only strategy for managing decision making. In fact, many teams may waste time and energy trying to come to a consensus when, in fact, the issue is not essential enough to warrant such effort. As Vroom notes in his model of leadership and decision making, the context of the decision, and the importance of the issue can lead one to other methods of decision making that will be more effective. ${ }^{12}$ Vroom identifies seven questions that managers can use to help determine when participatory methods may be most useful. First, is the quality of the decision important? If so, then participatory processes are needed. Does the leader have sufficient information to make the decision? The less information the leader has, the more likely it is that participatory processes are needed. Is the problem well structured? If not, participation is in order. How important is acceptance of the decision by subordinates likely to affect implementation? The more crucial acceptance becomes, the more participation is needed. How likely is a decision of the leader to be accepted? If the leader's decision is not likely to be accepted without debate, then more participation in the process is needed. Do participants and the organization share the same goals? When goals are shared, participation can succeed. How much con- flict is likely among subordinates? The more conflict is likely, the more participation is needed.

These seven questions can help managers choose among different decision-making methods depending on the situation at hand. The amount of participation can vary on a continuum from no participation (autocratic decision making) to some participation (consultative processes) to full participation (group consensus). When the quality of the decision is important, the leader does not have enough information, the problem is unstructured, subordinates must accept the decision and are unlikely to accept an autocratic decision, goals are shared, there may be some conflict, and there is time to discuss the issues, then participatory consensus decision making is in order. If the problem is structured, the leader has the information, the group is likely to accept the decision, and goals are not necessarily shared, then autocratic decision making may be in order. For example, in a crisis situation, where time is limited, and the leader has the information needed to make a decision and there is a high probability that the decision will be accepted by the group, the manager should probably make the decision and resolve the problem.

Another way to look at decision-making methods in the participatory model is outlined by Plunkett and Fournier. ${ }^{13}$ They identify four other methods of decision making in addition to consensus that teams can use effectively in reaching their goals. Majority vote can be used when the issue is relatively minor, and members can agree to go along with the majority but not necessarily support the results. For example, choosing a rotating secretary for team meetings may be done by majority vote. Unanimity is needed when 100 percent agreement among members is essential. This method is used for issues that define what processes the team will use to work together. Agreement on team values fits in this category. Some decisions can be imposed. When the issue is truly non-negotiable in terms of responsibility or has a low impact, the team leader may simply make the decision. For example, the location of meetings may be dictated by the team leader. Finally, the authors describe a process they call plop. This is the case where a suggestion gets accepted without any discussion. When the group has no formal agenda, leader or process or is hopelessly stalled, a team member may 
simply suggest an alternative and the group goes along. For example, someone can suggest the group describe the problem at hand and then immediately go on to describe the problem as she/he sees it, leaving others to follow with their perspectives.

\section{THE MODELS IN THE LIBRARY CONTEXT: EXAMPLES}

In a large complex organization all of these various models can be present at different times. What would such a library look like to a manager? Using a stereotypical, traditional library the manager might find that bureaucratic processes dominate technical services operation while political bargaining and garbage can processes are found in public service operations. Participatory processes and true teamwork models may be found in some small group operations such as a branch library or fairly independent units within the overall structure.

Technical services operations have traditionally been rule bound processes. Materials are acquired following business guidelines, standard accounting procedures and assorted legal requirements for purchasing operations. Cataloging follows standard operating procedures and rules imposed by national utilities and following national standards. These business processes within libraries lend themselves to bureaucratic approaches which can improve efficiency and lead to a streamlined operation as easily as they can create a mess of red tape and rules that make processing time consuming and expensive.

Public services operations have a different culture to them. In academic libraries liaison or reference librarians may be quite autonomous, blending their service to meet the needs of different academic disciplines and departments. Goals for each librarian may be different based on the differences they find in working with different units. Structure becomes difficult as the librarians seek flexibility in their ability to meet faculty and student demands. In this environment political bargaining behavior may dominate the group as individuals seek to meet their own objectives.

Garbage can behavior can appear anywhere in the organization where individuals can act independently of each other. In academic settings where librarians have a role in governance issues, they may have little incentive to work together as a coherent group, but may find that ad hoc groups are needed only as an issue attracts their attention. Once they lose interest in the issue at hand they can move on to other activities without necessarily resolving the problems that attracted their attention in the first place.

In systems with branch libraries the manager will often find that the culture in the branch is different from the culture of the main library. The branch staff may think of themselves as only loosely connected to the central or main library. Branch staff may develop into a participatory team where decision making and power are truly shared. Conversely they may use political bargaining behavior in efforts to negotiate with the central library over policies and procedures. To the branch staff, the central library may appear to be a very bureaucratic culture with unreasonable rules and regulations that do not fit the branch environment. They may see the central library as a coherent culture when in fact the culture within the departments of the central library varies. Bridging the gap between branch approaches and central library concerns becomes a true challenge for managers as they must bridge cultures and perceptions.

Since libraries are usually part of larger organizations, managers face having to understand the culture of the parent organization as well as the culture of their own unit. In universities the faculty may exhibit garbage can behavior while perceiving the library to be overly bureaucratic. They are not likely to recognize that the climate may vary by the type of department. Patrons may not understand that a political bargaining approach that may be effective in working with reference librarians may be ineffective when working with a more bureaucratic based circulation or acquisitions department. Frustration caused by misunderstanding between patrons and the library about organizational approaches can lead to complaints that are difficult to resolve.

The examples of different organizational approaches are endless. In practice, though, managers need to be able to recognize the dominant behavior or culture of a unit or staff and then approach the unit appropriately if they wish to succeed.

Alternately they can try to change the culture. For example, to bring in participatory processes requires that managers consciously try to change the overall organizational culture to promote shared 
goals and shared power. Bringing these values into a bureaucratic environment requires changing the basic pattern of behavior within the units, and extensive training for participants to become comfortable participating in an environment of uncertainty. Bringing these same values into a political bargaining operation is also a challenge because the manager will need to find ways to convince participants that organizational goals are more important than individual autonomy. The key for the manager is to recognize the types of changes that are needed and to address those in training programs to introduce the organizational changes.

\section{CONCLUSIONS}

In today's chaotic environment the ability to adapt to different organizational cultures is crucial if managers are to implement major changes and ensure that their organizations remain vital and successful. ${ }^{14}$ Planning change strategies and anticipating the consequences of these actions are basic skills for managers today. Trying to implement change using inappropriate strategies that do not match the prevailing organizational climate can lead to frustration and failure. Devising strategies that mesh with the organizational context can help ensure success.

Recognizing the different processes which may be present in the organization is the first step for managers. Learning which strategies are likely to succeed in each context is the next step. The challenge is then to develop strategies that can be used in more than one context and to develop strategies that can succeed when more than one organizational process is present. For example, in the library scenario given above, managers may be working with task forces that include staff from both technical services who are comfortable with bureaucratic structures and staff from public services who prefer to negotiate and bargain. In such cases the manager and the task force members can learn to adapt to each others' styles, can proceed with their own preferred styles and hope that a compromise can be reached, or they can create a different, commonly held style for that task force. For any of these approaches to succeed, participants must be aware of the different styles within the organization and with different options for managing within each style. When participants and managers are able to recognize and understand their differences, they are more likely to develop strategies that bring success to the group or organization.

Managers in complex organizations are likely to face the problem of identifying and working within multiple organizational models. To be successful managers must adapt their strategies to meet the needs of the individuals and groups within the organization. The framework provided in this article can be used to help managers distinguish among the different approaches present in complex organizations. Managers can then devise strategies to work effectively with different groups within their complex organizations.

\section{NOTES}

1. This analysis builds on the work done as part of the dissertation: Joan Giesecke, Making Decisions Under Chaotic Conditions (Ann Arbor, Mich.: University Microfilms, 1988). See also Joan Giesecke, "Recognizing Multiple Decisionmaking Models: A Guide for Managers," College \& Research Libraries 54 (1993): 103-114.

2. Richard Elmore, "Organizational Models of Social Program Implementation," Public Policy 26 (1978): 188-189; see also Graham Allison, "Conceptual Models and the Cuban Missile Crisis," American Political Science Review 63 (1969): 689-718; Lee Bolman and Terrence Deal, Modern Approaches to Understanding and Managing Organizations (San Francisco: Jossey-Bass, 1984); Jeffrey Pfeffer, Power in Organizations (Marshfield, Mass.: Pitman, 1981).

3. Henry Mintzberg, The Nature of Managerial Work (New York: Harper \& Row, 1973); Morgan W. McCall and Robert Kaplan, Whatever It Takes: Decision Makers at Work (Englewood Cliffs, N.J.: Prentice-Hall, 1985).

4. James Burns, Leadership (New York: Harper \& Row, 1979), 379; Richard Elmore, "Organizational Models," 191-199; Allison, "Conceptual Models," 689-718.

5. For a review of the political bargaining model see, Graham Allison, "Conceptual Models," 689-718; Bolman and Deal, Modern Approaches to Understanding Organizations; Charles Lindblom, "Science of Muddling Through," Public Administration Review 19 (1959): 79-88; Pfeffer, Power in Organizations.

6. Michael Cohen, James G. March, and Johan Olsen, "A Garbage Can Model of Organizational Choice," Administrative Science Quarterly 17 (1972): 1-19.

7. Elmore, "Organizational Models," 199-208; Allison, "Conceptual Models."

8. For a review of team development and when teams are most appropriate see Jon Katzenbach and Douglas Smith, The Wisdom of Teams: Creating the High Performance Organization (Mass.: Harvard Business School Press, 1993). 
9. Lee Bolman and Terrence Deal, "What Makes a Team Work," Organizational Dynamics 21 (1992): 34-44.

10. For strategies to use in political bargaining environment see: Bolman and Deal, Modern Approaches to Organizations; Anna Grandori, "A Prescriptive Contingency View of Organizations," Administrative Science Quarterly 29 (1984): 192-209; Lindblom, "Science of Muddling Through"; Pfeffer, Power in Organizations.

11. James G. March and Roger Weissinger-Baylon, Ambiguity and Command (Marshfield, Mass.: Pitman, 1968), 23-24; James G. March and Johan Olsen, Ambiguity and Choice in Organizations (Bergen: Universitetsforlaget, 1979), 78-79.

12. Victor Vroom and Arthur Jago, The New Leadership: Managing Participation in Organizations (Englewood Cliffs, N.J.: Prentice-Hall, 1988), 61.

13. Lorne C. Plunkett and Robert Fournier, Participative Management: Implementing Empowerment (New York: John Wiley \& Sons, 1991), 36-39.

14. For a further review of the issues of multiple organizational processes or cultures see Jean M. Bartunek and Michael K. Moch, "Multiple Constituencies and the Quality of Working Life: Intervention at FoodCom" in Peter J. Frost, ed., Reframing Organizational Culture (California: Sage Publications, 1991). 